\title{
Gaq Mediates Clozapine Effects in Caenorhabditis elegans
}

3 Limin Hao*§, Yongguang Tong ${ }^{\dagger}$, Kristin Harrington*, Jessica L. O’Neill ${ }^{*}$ Afsaneh

4 Sheikholeslami*, Xin Wang*, Jonathan H. Freedman ${ }^{*}$, Bruce M. Cohen ${ }^{*}$, Edgar A. Buttner*

5

6 *§ Program for Neuropsychiatric Research, McLean Hospital, Belmont, MA 02478, USA

$7 \quad$ Laboratory of Toxicology and Pharmacology, National Institute of Environmental Health

8 Sciences, Research Triangle Park, NC 27709, USA

9 Department of Pharmacology and Toxicology, University of Louisville School of Medicine,

10 Louisville, KY 40202, USA

$11 \S$ Corresponding author. 
12 Running title: Gaq Mediates Clozapine Effects

13 Keywords: Caenorhabditis elegans, clozapine, dopamine receptor, egl-30, Gaq

14

15 Correspondence:

16 Limin $\mathrm{Hao}, \mathrm{PhD}$

17 Address: 115 Mill Street, McLean Hospital, Belmont 02478, USA

18 Email: 1hao1969@gmail.com

19 Phone: 781-827 1240 


\section{ABSTRACT}

21 Clozapine binds and has significant effects on multiple neurotransmitter receptors, notably

22 including some dopamine receptors. Downstream of these receptors, clozapine affects the

23 balance of Gi- and Gq-dependent second-messenger signaling. We used Caenorhabiditis elegans

24 as a genetic model to study further how clozapine affects both dopamine receptors and

25 downstream Gq mediated signaling. Four of six worm dopamine receptor orthologs, dop-1, dop-

26 2, dop-4, and dop-5 produced resistance to clozapine induced developmental delay when

27 mutated, suggesting that both type I and type II dopamine receptors mediate the behavioral

28 effects of clozapine in C. elegans. Beyond these receptors, reduction of function of one of the G

29 proteins, egl-30 (Gaq), produced greatly increased susceptibility to clozapine. Gaq has multiple

30 known downstream effects. Among these is the control of acetylcholine release, which is in

31 balance with monoamines in the human brain and is another target of clozapine and other

32 antipsychotic drugs. We tested for downstream effects on acetylcholine at the neuromuscular

33 junction upon clozapine treatment but found no evidence for effects of clozapine. In contrast,

34 modulation of Gaq upstream leads to worms that are either more resistant or more susceptible to

35 clozapine, emphasizing the importance of Gaq proteins in mediating effects of clozapine. A

36 genetic screen for suppressors of egl-30 recovered eight mutants. By characterizing the

37 behavioral effects of these mutants, we found that clozapine exerts its function on development

38 by affecting Gaq signaling through control of the pharyngeal pumping rate. A whole-genome

39 sequencing technique was utilized and identified a list of candidate genes for these suppressor

40 mutations. Further characterization of these mutants promises the discovery of novel components

41 participating in Gaq signaling and a better understanding of the mechanisms of action of

42 clozapine. 


\section{Introduction}

44 Clozapine is an atypical antipsychotic drug (APD), mainly used for schizophrenia that does not

45 improve following the use of standard antipsychotic medications. The pharmacology of

46 clozapine shares some features with other APDs, but other features are unique, and its sites of

47 action are especially complex.

49 Standard antipsychotic drugs are thought to achieve some of their important effects (both

50 beneficial and unwanted) by acting as antagonists or partial agonists at D2 receptors (JONES AND

51 PILOWSKY 2002). In humans, there are five distinct G-protein coupled dopamine (DA) receptors,

52 and they are divided into two major subtypes: D1-like (D1 and D5) and D2-like (D2, D3 and D4)

53 (CUMming 2011). These two classifications were originally assigned based on the receptor's

54 effect on cyclic AMP levels, but also reflect genetic homologies. Selective pharmacological

55 agents and receptor knockouts have been applied to demonstrate that signaling through D1-like

56 and D2-like receptors have opposite effects on many aspects of cell activation and some

57 behaviors (Kelly et al. 1998; GONG et al. 1999; MCNAMARA et al. 2003). However,

58 simultaneous stimulation of both D1 and D2 type receptors shows that these receptors also have

59 synergistic effects on certain behaviors (PLAZNIK et al. 1989; GONG et al. 1999). By comparison

60 to standard antipsychotic medications, clozapine binds weakly to D2, more strongly to D4,

61 among dopamine type II receptors, and most strongly to Type I dopamine receptors, including

62 the D1 receptor. It also binds with high affinity to histamine (H1), acetylcholine muscarinic

63 (M1), $\alpha$-adrenergic ( $\alpha 1$ ), and multiple serotonin $\left(5-\mathrm{HT}_{2 \mathrm{~A}}, 5-\mathrm{HT}_{2 \mathrm{C}}, 5-\mathrm{HT}_{7}\right)$ receptors (NAHEED

64 AND GREEN 2001). 
The Caenorhabditis elegans (C. elegans) genome encodes six genes for dopamine receptors, and

66

67

68

four of these genes have been validated as orthologous to human DA genes, based on sequence similarities, pharmacological profiles, and biochemical properties (SUO et al. 2002; SUO et al. 2003; CHASE et al. 2004; SUGIURA et al. 2005). As in humans, these receptors are divided into two categories with opposite effects in modulating cyclic AMP levels; agonists at dop-1 and dop4 upregulate cyclic AMP levels and agonists at dop-2 and dop-3 do the opposite. The other two orthologs, T02E9.3 and C24A8.1, named dop-5 and dop-6, have similarities to the dop-3 sequence, but they have not yet been experimentally validated to be D2-like. Signaling transduction mediated by these dopamine receptors controls multiple worm behaviors, including locomotion, egg laying, defecation, basal motor activity, sensation/response to food sources, and habituation to touch (MCDONALD et al. 2006). DOP-1 and DOP-3 have antagonistic effects on locomotion, by acting in the same motor neurons, which co-express the receptors and which are not postsynaptic to dopaminergic neurons.

Direct effects on DA and other receptors are the start of a cascade of reactions which next passes through $\mathrm{G}$ proteins, as second messengers. A non-biased genetic screen identified two antagonistic G proteins, Gao and Gaq, activated by these receptors and mediating their downstream effects (CHASE et al. 2004). G $\alpha$-GTP and G $\beta \gamma$ dimers transmit receptor-generated signals to downstream effector molecules and protein-binding partners until the intrinsic GTPase activity of Ga hydrolyzes GTP to GDP and the inactive subunits re-associate. G proteins are localized and function primarily at the plasma membrane, in contact with cell surface receptors, but also function intracellularly at endosomes (SLESSAREVA et al. 2006)., Gaq activates phospholipase C- $\beta$ (PLC $\beta$ ), thereby generating the second messengers inositol-1,4,5-triphosphate 
88 (IP3) and diacylglycerol (DAG). These, in turn, release stored $\mathrm{Ca}^{2+}$ and activate protein kinase $\mathrm{C}$.

89 Gaq also activates GEF p63RhoGEF (ARHGEF25) and its homologs Trio and Duet. These

90 tertiary messengers subsequently modulate numerous enzymatic processes, metabolic pathways,

91 components of the cytoskeleton and the release of extracellular signaling molecules.

93 C. elegans has $21 \mathrm{G} \alpha, 2 \mathrm{G} \beta$ and $2 \mathrm{G} \gamma$ genes and it expresses one ortholog of each of the four 94 mammalian families GSA-1(Gs), GOA-1(Gi/o), EGL-30 (Gq) and GPA-12 (G12). The

95 remaining C. elegans $\mathrm{G} \alpha$ subunits do not share sufficient homology to mammalian Ga proteins

96 to allow classification (BASTIANI AND MENDEL 2006). They may play roles similar to the four

97 types of G proteins, e.g., GPA-14 is able to interact with DOP-2 and shows close similarity to

98 inhibitory G proteins that modulate anterior touch habituation and chemosensory associative

99 conditioning (PANDEY AND HARBINDER 2012; MERSha et al. 2013). In a fully studied C. elegans

100 neural muscular junction, it has been discovered that a network of $G$ protein signaling pathways

101 controls the release of synaptic vesicles and/or dense-core vesicles (PEREZ-MANSILLA AND

102 NURRISH 2009). The Gaq, Ga12 and Gao pathways converge to control production and

103 destruction of the lipid-bound second messenger DAG at sites of neurotransmitter release. DAG

104 subsequently acts via at least two effectors, MUNC13 and PKC, to control the release of both

105 neurotransmitters and neuropeptides from motor neurons. The Gas pathway converges with three

106 other heterotrimeric G-protein pathways downstream of DAG to regulate neuropeptide release

107 (BASTIANI AND MENDEL 2006). 
109 G protein mediated effects of clozapine have been studied in cultured cells and mammals. In

110 cultured PC12 cells, clozapine downregulates the expression of tyrosine hydroxylase. This effect

111 can be abolished by treatment with $\mathrm{N}$-ethylmaleimide, a reagent that decouples Gi/o protein from

112 its adjunct receptors, suggesting that clozapine modulates Gi/o protein signaling pathways

113 (TEJEDOR-REAL et al. 2005). In the rat brain, the serotonin receptor, 5-HT2A, recruits Gq

114 proteins promoting PLC stimulation, and clozapine antagonizes 5-HT-induced phosphoinositide

115 (PI) hydrolysis, probably by inhibiting Gq proteins (MANNOURY LA COUR et al. 2009). Recently,

116 it has been found that clozapine binds the mGluR2/2AR receptor heterocomplex, which also

117 alters the balance of Gi- and Gq-dependent signaling (FRIBOURG et al. 2011).

119 In our laboratory, we have used the well-documented clozapine-induced developmental

120 delay/lethality phenotype in C. elegans to study the mechanisms of action of clozapine. We

121 performed a genome-wide RNAi screen and identified 40 genes suppressing the effects of

122 clozapine and characterized some of these genes (SAUR et al. 2013; WANG et al. 2014; HAO et

123 al. 2016). To increase understanding of specific mechanisms underlying these findings, we now

124 take advantage of the known effects of clozapine on dopamine receptors and extend them to the

125 study of downstream effects on $\mathrm{G}$ protein signaling pathways. The new findings suggest that a

126 known $\mathrm{G}$ protein signaling downstream pathway is unaffected, but a non-biased genetic screen

127 revealed new $\mathrm{G}$ protein pathway components that could mediate effects of clozapine. 


\section{Nematode growth and worm strains}

131 Nematodes were cultured on NGM plates in a $20^{\circ} \mathrm{C}$ incubator (LEWIS AND FLEMING 1995). The

132 wild type N2 worm was used in these experiments as a control species. Other worm strains used

133 are listed as follows: DA1077: egl-30(ad810);dpy-5(e61)/szT1[lon-2(e678)];+/szT1, EAB66-71

134 and EAB73-74: suppressors of egl-30(n686), LX645: dop-1(vs100), LX702: dop-2(vs105),

135 LX703: dop-3(vs106), LX704: dop-2(vs105);dop-3(vs106), LX705: dop-1(vs 100);dop-3(vs 106),

LX706: dop-1(vs 100);dop-2(vs105), LX734: dop-1(vs100);dop-2(vs105);dop-3(vs106),

MT1434: egl-30(686), MT2609: egl-30(n715n1190), NM1380: egl-30(js126), PS2444: dpy-

20(e1282);syIs36, PS4263: egl-30(md186);dpy-20(e1282);syIs105, RB1254: dop-4(ok1321),

RB1680: dop-6(ok2090), RB785: dop-5(ok568). The other worm strains employed can be seen in

Table 1.

\section{Developmental drug assay}

143 The developmental drug assay was performed as previously described in (HAO AND BUTTNER 2014). In brief, well-grown adult animals were treated in bleach solution (hypochlorite: $1 \mathrm{~N}$

146 12-well NGM assay plates containing variable concentrations of drugs. The drugs were initially

147 dissolved in DMSO to obtain $80 \mathrm{mM}$ stock solutions, which were diluted into $1.7 \mathrm{mM}$ acetic

148 acid. Treated worms were transferred onto the NGM plates. Every 24 hours thereafter, the plates

149 were observed and the developmental status of the worms was recorded. For each worm strain,

150 the experiment was repeated at least three times. The concentration of clozapine was adjusted 
151 according to the sensitivity of the tested worm strain. We present results from the third day of

152 observation, as results at this time optimally identify and represent the phenotype of strains with

153 different growth characteristics.

155 Worm Behavioral assays

156 The worms used for behavioral assays were staged young adult worms. Unless stated otherwise,

157 these were obtained by picking well-grown L4 worms onto NGM plates $24 \mathrm{~h}$ before the assay to

158 allow them grow to young adulthood. For the pharyngeal pumping assay, ten worms were placed

159 on NGM assay plates containing various concentrations of drugs, allowed to adapt for $30 \mathrm{~min}$,

160 then, the number of contractions of the pharyngeal bulb was counted for $20 \mathrm{~s}$ for each worm. For

161 the aldicarb assay, the NGM plates were supplemented with $1 \mathrm{mM}$ aldicarb. Thirty worms were

162 placed onto the assay plates, observed every $30 \mathrm{~min}$ and scored as moving or paralyzed worms.

163 Paralyzed worms did not move when poked by the worm pick. For the locomotion assay, ten

164 young adult worms were placed on NGM plates seeded with OP50 E. coli. After adaptation for 5

$165 \mathrm{~min}$, the number of wiggles of the body was counted for $30 \mathrm{~s}$ for each worm. For the egg

166 retention assay, well-fed young adult worms were picked onto NGM plates with food and

167 allowed to grow for $24 \mathrm{~h}$. The assayed worms were picked onto a slide with an agarose pad with

$16820 \mathrm{mM}$ sodium azide, and observed under a Zeiss Axio2 microscope using the 100x objective

169 lens. The number of eggs in the belly were counted. All assays were repeated three times and

170 two-tail t-tests were used to compare the mutant strain with the control strain.

171

172 Genetic screen for suppressors of egl-30(n686) 
173 Synchronized L4 worms were treated with $50 \mu \mathrm{M}$ ethyl methanesulfonate and shaken for $4 \mathrm{hrs}$.

174 The treated worms (P0) were collected and washed twice with M9 buffer and transferred onto

175 two NGM plates to grow for $24 \mathrm{hrs.} \mathrm{Ten} \mathrm{adult} \mathrm{worms} \mathrm{were} \mathrm{transferred} \mathrm{onto} \mathrm{each} \mathrm{of} \mathrm{ten} \mathrm{fresh}$

176 plates and allowed to lay eggs for $4 \mathrm{hrs}$. Then they were transferred onto another ten fresh plates

177 and allowed to lay eggs (F1) overnight. After they grew to adulthood, ten F1 worms were

178 transferred onto $60 \mathrm{NGM}$ plates containing 250 or $350 \mu \mathrm{M}$ clozapine, and allowed to lay eggs

179 (F2) overnight. After 1-2 days, ten surviving F2 worms were transferred onto each of 60 NGM

180 plates and allowed to grow to adulthood. Then six F2 worms were transferred onto NGM plates

181 containing $300 \mu \mathrm{M}$ clozapine (egl-30(n686) was also picked as a control) and allowed to lay 25

182 eggs (F3), after which the adult worms were removed. After 2-3 days, if there were more worms

183 surviving in a plate compared to the egl-30 control, the plate of worms were classified as likely

184 suppressors. The suppressors were recovered and validated by testing them with a standard

185 clozapine developmental delay assay (HAO AND BUTTNER 2014).

186

187 Whole-genome sequencing and data analysis

188 Worms were grown on 10-20 $8.5 \mathrm{~cm}$ NGM plates until they were gravid adults, then washed

189 with M9 buffer into a $50 \mathrm{ml}$ tube and centrifuged at 2000xg for $3 \mathrm{~min}$. The supernatant was

190 removed and $30 \mathrm{ml}$ of bleach solution was added. Then the tube was inverted for 7-10 min until

191 all the worms were dissolved, followed by centrifugation at 1500xg for $1 \mathrm{~min}$ to collect eggs.

192 The eggs were washed once with M9 buffer, transferred onto $105.5 \mathrm{~cm}$ unseeded NGM plates,

193 and incubated overnight to allow the eggs to hatch. The hatched L1 worms were washed off the

194 plates with M9 buffer and collected by centrifugation at 1500xg for $1 \mathrm{~min}$, then washed twice

195 with M9 buffer. The clean L1 worms were used immediately or stored at $-80^{\circ} \mathrm{C}$. DNA was 
196 isolated via a Gentra Puregene Kit (Qiagen). The concentration of the final DNA preparation was

197 determined using the Qubit assay (Invitrogen). $1 \mu \mathrm{g}$ DNA was used for preparing the sequencing

198 library according to the TruSeq ${ }^{\circledR D N A}$ PCR-free sample preparation kit (Illumina). DNA

199 sequencing was performed using an Illumina HiSeq sequencer.

200

201 The sequencing results were analyzed at the high-performance computation facility of the

202 Partners Healthcare System. The reads were mapped to the reference genome (WS220) with

203 Bowtie-0.12.7, and the variant calls were done with Samtools. The variants were checked in igv.

204 We only focused on mutations that occurred in coding regions and splicing sites at which

205 variants could potentially cause disturbance of protein structures.

207 Strains are available upon request. 


\section{Results}

\section{Dopamine receptors mediate effects of clozapine}

210 There are six dopamine receptor orthologs in the C. elegans genome, and mutants in each

211 ortholog are available. We performed developmental assays by growing the mutants and wild

212 type worms in plates treated with $0,300,400$, and $500 \mu \mathrm{M}$ clozapine. As shown in Fig. 1A, the

213 lethality rate of wild type worms was high and surviving worms were at the L1 stage. By

214 comparison, the lethality rates of dop-1, dop-2, dop-2;dop-3, dop-1;dop-3, dop-1:dop-2, dop-

215 1;dop-2;dop-3 mutants were much lower and some of the worms developed to the L2 stage. By

216 comparison, the lethality rate of $d o p-3$ mutants was as high as that of the wild type strain. These

217 observations, that $d o p-1$ and $d o p-2$ mutants were resistant to clozapine, while $d o p-3$ mutants

218 were not resistant to clozapine, suggest that both $d o p-1$ and $d o p-2$ mediate effects of clozapine,

219 but dop-3 does not. We also tested mutants of the other three dopamine receptors, dop-4, dop-5

220 and $d o p-6$, and found that $d o p-4$ and $d o p-5$ mutants were resistant to the effects of clozapine, but

221 dop-6 mutants were not (Fig. 1B).

\section{Gaq proteins mediate effects of clozapine}

224 Dopamine receptors are $\mathrm{G}$ protein coupled, and the alpha subunit of $\mathrm{G}$ protein has been found to 225 be associated with the effects of clozapine in mammalian models. To test for this association in C. elegans, we studied mutants of the Gaq ortholog, egl-30, in worms. Compared to wild type,

227 the lethality rate of a reduction of function $(r f)$ mutant, egl-30(n686), was dramatically increased 228 and development was delayed. Conversely, the lethality rate of a constitutively active mutant, 229 egl-30(js 126), was slightly reduced and development was promoted (Fig. 2A). To confirm this 
230 observation, we conducted drug assays on two other $r f$ mutant alleles, egl-30(ad810) and egl-

$23130(n 715 n 1190)$, and found that they were also susceptible to clozapine (Fig. 2B). We also tested

232 two worm strains carrying the integrated transgene of egl-30 DNA sequence in either wild type

233 background or an egl-30 mutation background, supposed to have higher Gaq level than wild

234 type, and found that they both reduced lethality rates and promoted development, compared to

235 wild type (Fig. 2B).

Various known downstream components of the Gaq signaling transduction pathway are not involved in mediating effects of clozapine

239 The egl-30 gene is expressed ubiquitously and required for worm viability, locomotion, egg

240 laying, synaptic transmission and pharyngeal pumping. We used egg laying and locomotion

241 phenotypes to study downstream behavioral effects of changes in Gq signaling pathways. We

242 also studied one pathway related to synaptic transmission. G $\alpha$ protein-involved signaling

243 controls the release of acetylcholine and other neuropeptides (Fig. 3).

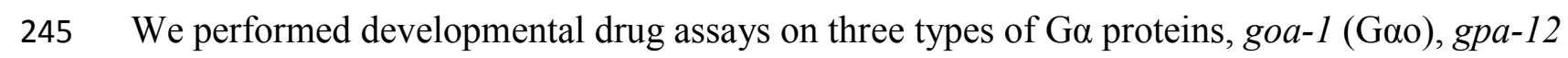

246 (Ga12), gsa-1 (Gas) and found that their mutants are no different than wild type in response to 247 clozapine (Fig. 3 and Table 1).

249 In the Gq and Gas signaling pathways, we conducted developmental drug assays on the

250 downstream components of the Gq signaling pathway, namely, egl-8, unc-73, dgk-1, unc-13, 
$251 p k c-1$, and found that $d g k-1$ suppressed the effects of clozapine, while egl- 8 was similar to wild

252 type or slightly suppressed the effects of clozapine. By comparison, unc-73, unc-13, and pkc-1

253 strains all responded to clozapine the same as wild type strains (Table 1). In addition,

254 developmental drug assays performed on the downstream components of the Gas signaling

255 pathway, acy-1, pde-4, and kin-2, showed that they all responded to clozapine the same as wild

256 type strains (Table 1). These observations suggested that these known downstream components

257 of $\mathrm{Gq}$ and other $\mathrm{G} \alpha$ signaling pathways were not involved in mediating the effects of clozapine.

\section{Gaq modulators alter effects of clozapine}

260 We investigated the role of modulators of Gaq by conducting developmental assays and

261 discovered that mutants of ric-8, a non-receptor activator of Gaq in both C. elegans and

262 mammals, are resistant to clozapine (Fig. 3, Table 1). Mutants of three other modulators of Gaq,

$263 c n b-1$, eat-16, and $r s b p-1$ were found to be more susceptible to clozapine (Table 1).

\section{Isolation and characterization of Gaq mutant suppressors of clozapine effects}

We performed a forward genetic screen for suppressors of egl-30(n686), taking advantage of the hypersensitivity of egl-30(n686) to clozapine. We found eight mutants that were more resistant to clozapine than egl-30(n686), and these suppressors were named EAB66-71 and EAB73-74.

269 The strongest suppressor was EAB66, which was even more resistant to clozapine than wild type

270 (data not shown). We characterized these mutants for other behavioral phenotypes and compared

271 them to wild type and egl-30(n686) worms. Aldicarb is an inhibitor of cholinesterase, causing

272 rapid accumulation of acetylcholine at the synaptic cleft, and thereby paralysis of the worms. The 
273 egl-30(n686) mutant is resistant to aldicarb compared to wild type. The suppressor EAB66 is

274 phenotypically like the wild type worm, whereas EAB67 remains phenotypically like the egl-

$27530(n 686)$ worm (Fig. 4A). In the locomotion assay, strains carrying the suppressor EAB66 move

276 faster than egl-30(n686), but they do not move at the wild type level; whereas the EAB67 strain

277 is even slower than egl-30(n686) (Fig. 4B). As for the egg retention assay, EAB66 and EAB67

278 strains are both more similar to egl-30(n686) strains than wild type worms (Fig. 4C). However,

279 in the pharyngeal pumping assay, all the suppressors show activity that is statistically

280 significantly different from egl-30(n686), except EAB73 at $450 \mu \mathrm{M}$ (Fig. 4D).

282 Candidate genes for Gaq suppressors revealed by whole-genome sequencing

283 To identify the specific genes coding for the suppressor mutants, we performed whole-genome

284 sequencing of these mutants and compared the sequences of wild type and egl-30(n686) worms.

285 As shown in Table 2, there are two to five mutations occurring in these mutants, each of which

286 changes protein coding sequences. Most of the mutations introduce a stop codon in a coding

287 region; but there are four mutations that change splicing sites; and one mutation changes the

288 initial start codon $(\mathrm{M} / \mathrm{V})$ in EAB68 (Table 2). 


\section{Discussion}

290

291

292

293

294

295

296

297

298

299

300

301

302

303

304

305

306

307

308

309

310

311

In the worm model, dopamine receptors participate in mediating the effects of clozapine in producing developmental delay/lethality. Interestingly, when mutated, four out of six dopamine receptors, including both type I and type II dopamine receptors, relieve clozapine-induced developmental phenotypes (Fig. 1). These findings cannot be explained by the simple model in which the two types of dopamine receptors have purely opposite and competing effects at the level of production of cAMP, through activation of Gas and Gao. Our observation that neither

Gas nor Gao mutants display behavioral differences from wild type strains in drug assays is also consistent with a more complex interaction of dopamine receptors and G proteins (Table 1).

Notably, there is growing evidence that G protein coupled receptors (GPCRs) execute their functions through oligomerization, including homomerization and heteromerization (FERRE AND FRANCO 2010). Oligomerization allows receptors to achieve new properties, including changes in ligand recognition, G protein-coupling and trafficking (FERRE AND FRANCO 2010). For example, while the D1-D3 receptor heteromer couples to Gs (FIORENTINI et al. 2010), the D1-D2 and D2-D5 heteromers couple preferentially to Gq proteins (HASBI et al. 2010). Clozapine may exert its effects on development through interactions with and modulation of such oligomers of dopamine receptors.

\section{Based on our genetic studies on the components in the four $\mathrm{G}$ protein-involved signaling} networks (Fig. 2, Table 1), only Gq and its modulators appear to strongly mediate the effects of clozapine. The classical model that Gs and Go balance cAMP production and metabolism is not supported by our findings, since the mutants of Gs and its downstream components do not differ from wild type in their drug response. Gq and Go may form a signaling balance as suggested by 
312 Fribourg et al. (FRIBOURG et al. 2011). A Go/Gq heterotrimeric G protein signaling network

313 expressed throughout the nervous system has been shown to regulate locomotion rate, partly by

314 affecting serotonergic neurotransmission. And loss-of-function (lf) mutations in goa-1 (Gao)

315 cause hyperactivity, whereas If mutations in egl-30 (Gaq) cause severe lethargy (MILLER et al.

316 1999; NURRISH et al. 1999). However, while egl-30 Gaq mutants are highly susceptible to

317 clozapine (Fig. 2), the goa-1 (Gao) mutant does not display a resistant phenotype upon clozapine

318 treatment (Table 1). Furthermore, the downstream components, i.e., in the PLC signaling

319 pathway that facilitates synaptic transmission by body-wall muscle motor neurons, do not appear

320 to mediate clozapine effects, as their mutants have the same response as wild type strains (Table

321 1). Taken together, these observations indicate that the effects of clozapine on worm

322 development are not mediated by these known Gaq downstream signaling elements.

324 To explore how Gq proteins mediate the effects of clozapine, we performed a genetic screen and

325 identified eight suppressing mutants that were more resistant to the behavioral effects of

326 clozapine than the $r f$ of egl-30 strain. Since the $r f$ of egl-30 exhibited phenotypes including

327 decreased pharyngeal pumping and locomotion rates, reduced sensitivity to aldicarb, and high

328 retention of eggs, we tested whether these behaviors were affected by the suppressing mutations.

329 We tested two suppressors, EAB66 and EAB67, and found that aldicarb sensitivity, locomotion

330 rate and egg retention were changed at baseline in ways similar to egl-30, but EAB66 and

331 EAB67 did not have the characteristics of egl-30 in altering response to clozapine (Fig. 4). The

332 genes affected by these suppressors might not be involved in the developmental/lethality

333 phenotypes induced by clozapine. In contrast, the pharyngeal pumping rates of all the

334 suppressors recovered to the wild type levels (Fig. 4), indicating that this behavior does 
335 correspond to the effects of clozapine on development, which is in agreement with our

336 previously reported findings (HAO et al. 2016).

338 Whole-genome sequencing revealed that each mutant strain carried 2-5 mutations that would

339 likely change protein structures. Most of the candidate genes in these suppressors are novel.

340 Further studies may identify the components that mediate the effects of clozapine through the Gq

341 protein.

343 In summary, we studied the actions of clozapine, using C. elegans as a genetic model, and

344 observed that both type I and type II dopamine receptors mediate the behavioral effects of

345 clozapine. Further, the results suggest that dopamine receptors form oligomers to signal through

346 Gq proteins. We also found that clozapine exerts its function on development by modulating Gq

347 signaling, which controls the pharyngeal pumping rate. The mutants we identified can be studied

348 further and those studies promise more interesting discoveries involving Gq signaling and a

349 better understanding of the mechanism of action and effects of clozapine beyond its direct effects 350 on cell surface receptors. 


\section{Acknowledgements}

352 Some strains were provided by the CGC, which is funded by the NIH Office of Research

353 Infrastructure Programs (P40 OD010440). We thank Dr. Michael Koelle at Yale University, Dr.

354 Masahiro Tomioka at University of Tokyo, Dr. Paul W. Sternberg at California Institute of

355 Technology, Satoshi Suo at University of Tokyo at Komaba for providing worm strains and

356 other materials. We thank the Enterprise Research Infrastructure \& Services (ERIS) at Partners

357 HealthCare for their support in the genome analysis. This work is dedicated to the memory of Dr.

358 Edgar (Ned) A. Buttner, who passed away on October 15, 2015, for his inspiring enthusiasm,

359 warm collegiality and excellence in science.

361 The work was supported by an NIH Clinical Scientist Development award, K08NS002083, funds

362 of the Program for Neuropsychiatric Research, at McLean Hospital, and a NARSAD Young

363 Investigator Award to Edgar A. Buttner. 


\section{References}

Bastiani, C., and J. Mendel, 2006 Heterotrimeric G proteins in C. elegans. WormBook: 1-25.

Chase, D. L., J. S. Pepper and M. R. Koelle, 2004 Mechanism of extrasynaptic dopamine signaling in Caenorhabditis elegans. Nat Neurosci 7: 1096-1103.

Cumming, P., 2011 Absolute abundances and affinity states of dopamine receptors in mammalian brain: A review. Synapse 65: 892-909.

Ferre, S., and R. Franco, 2010 Oligomerization of G-protein-coupled receptors: a reality. Curr Opin Pharmacol 10: 1-5.

Fiorentini, C., C. Busi, P. Spano and C. Missale, 2010 Dimerization of dopamine D1 and D3 receptors in the regulation of striatal function. Curr Opin Pharmacol 10: 87-92.

Fribourg, M., J. L. Moreno, T. Holloway, D. Provasi, L. Baki et al., 2011 Decoding the signaling of a GPCR heteromeric complex reveals a unifying mechanism of action of antipsychotic drugs. Cell 147: 1011-1023.

Gong, W., D. B. Neill, M. Lynn and J. B. Justice, Jr., 1999 Dopamine D1/D2 agonists injected into nucleus accumbens and ventral pallidum differentially affect locomotor activity depending on site. Neuroscience 93: 1349-1358.

Hao, L., O. Ben-David, S. M. Babb, A. H. Futerman, B. M. Cohen et al., 2016 Clozapine Modulates Glucosylceramide, Clears Aggregated Proteins and Enhances ATG8/LC3 in Caenorhabditis elegans. Neuropsychopharmacology (In press, available online).

Hao, L., and E. A. Buttner, 2014 Methods for studying the mechanisms of action of antipsychotic drugs in Caenorhabditis elegans. J Vis Exp: e50864.

Hasbi, A., B. F. O'Dowd and S. R. George, 2010 Heteromerization of dopamine D2 receptors with dopamine D1 or D5 receptors generates intracellular calcium signaling by different mechanisms. Curr Opin Pharmacol 10: 93-99.

Jones, H. M., and L. S. Pilowsky, 2002 Dopamine and antipsychotic drug action revisited. Br J Psychiatry 181: 271-275.

Kelly, M. A., M. Rubinstein, T. J. Phillips, C. N. Lessov, S. Burkhart-Kasch et al., 1998 Locomotor activity in D2 dopamine receptor-deficient mice is determined by gene dosage, genetic background, and developmental adaptations. J Neurosci 18: 3470-3479.

Lewis, J. A., and J. T. Fleming, 1995 Basic culture methods. Methods Cell Biol 48: 3-29.

Mannoury La Cour, C., C. Chaput, M. Touzard and M. J. Millan, 2009 An immunocapture/scintillation proximity analysis of $\mathrm{G}$ alpha $\mathrm{q} / 11$ activation by native serotonin $(5-\mathrm{HT}) 2 \mathrm{~A}$ receptors in rat cortex: blockade by clozapine and mirtazapine. Synapse 63: 95-105.

McDonald, P. W., T. Jessen, J. R. Field and R. D. Blakely, 2006 Dopamine signaling architecture in Caenorhabditis elegans. Cell Mol Neurobiol 26: 593-618.

McNamara, F. N., J. J. Clifford, O. Tighe, A. Kinsella, J. Drago et al., 2003 Congenic D1A dopamine receptor mutants: ethologically based resolution of behavioural topography indicates genetic background as a determinant of knockout phenotype. Neuropsychopharmacology 28: 86-99.

Mersha, M., R. Formisano, R. McDonald, P. Pandey, N. Tavernarakis et al., 2013 GPA-14, a Galpha(i) subunit mediates dopaminergic behavioral plasticity in C. elegans. Behav Brain Funct 9: 16.

Miller, K. G., M. D. Emerson and J. B. Rand, 1999 Goalpha and diacylglycerol kinase negatively regulate the Gqalpha pathway in C. elegans. Neuron 24: 323-333.

Naheed, M., and B. Green, 2001 Focus on clozapine. Curr Med Res Opin 17: 223-229.

Nurrish, S., L. Segalat and J. M. Kaplan, 1999 Serotonin inhibition of synaptic transmission: Galpha(0) decreases the abundance of UNC-13 at release sites. Neuron 24: 231-242. 
Pandey, P., and S. Harbinder, 2012 The Caenorhabditis elegans D2-like dopamine receptor DOP-2 physically interacts with GPA-14, a Galphai subunit. J Mol Signal 7: 3.

Perez-Mansilla, B., and S. Nurrish, 2009 A network of G-protein signaling pathways control neuronal activity in C. elegans. Adv Genet 65: 145-192.

Plaznik, A., R. Stefanski and W. Kostowski, 1989 Interaction between accumbens D1 and D2 receptors regulating rat locomotor activity. Psychopharmacology (Berl) 99: 558-562.

Saur, T., S. E. DeMarco, A. Ortiz, G. R. Sliwoski, L. Hao et al., 2013 A genome-wide RNAi screen in Caenorhabditis elegans identifies the nicotinic acetylcholine receptor subunit ACR-7 as an antipsychotic drug target. PLoS Genet 9: e1003313.

Slessareva, J. E., S. M. Routt, B. Temple, V. A. Bankaitis and H. G. Dohlman, 2006 Activation of the phosphatidylinositol 3-kinase Vps34 by a G protein alpha subunit at the endosome. Cell 126: 191-203.

Sugiura, M., S. Fuke, S. Suo, N. Sasagawa, H. H. Van Tol et al., 2005 Characterization of a novel D2-like dopamine receptor with a truncated splice variant and a D1-like dopamine receptor unique to invertebrates from Caenorhabditis elegans. J Neurochem 94: 1146-1157.

Suo, S., N. Sasagawa and S. Ishiura, 2002 Identification of a dopamine receptor from Caenorhabditis elegans. Neurosci Lett 319: 13-16.

Suo, S., N. Sasagawa and S. Ishiura, 2003 Cloning and characterization of a Caenorhabditis elegans D2like dopamine receptor. J Neurochem 86: 869-878.

Tejedor-Real, P., R. Vogel, J. Mallet and N. F. Biguet, 2005 Gi/Go protein-dependent presynaptic mechanisms are involved in clozapine-induced down-regulation of tyrosine hydroxylase in PC12 cells. J Neurosci Res 81: 739-745.

Wang, X., C. W. Piccolo, B. M. Cohen and E. A. Buttner, 2014 Transient receptor potential melastatin (TRPM) channels mediate clozapine-induced phenotypes in Caenorhabditis elegans. J Neurogenet 28: 86-97. 


\section{Figure Legends}

436

437

438

439

440

441

442

443

444

445

446

447

448

449

450

451

452

453

454

455

456

Fig. 1. Dopamine receptors mediate clozapine effects. (A) Dopamine receptor mutantss, dop1(vs100), dop-2(vs 105), dop-3(vs 106), and combinations of these mutants, dop-2(vs105);dop3(vs106), dop-1(vs100);dop-3(vs106), dop-2(vs105);dop-3(vs106), dop-1(vs100);dop2(vs 105);dop-3(vs106) were treated with clozapine at 0, 300, 400, $500 \mu \mathrm{M}$. (B) Dopamine receptor mutants, dop-4(ok1321), dop-5(ok568), and dop-6(ok2090) were treated with clozapine at $0,300,400,500 \mu \mathrm{M}$.

Fig. 2. Gaq mediates clozapine effects. (A) Two Gaq mutants, one reduction of function ( $r f$ ) mutant egl-30(686) and one constitutive activity mutant egl-30(js126), was compared with that of the wild-type $\mathrm{N} 2$ strain by testing them in a series of concentrations of clozapine at $0,50,100$, 150, 200, 250, 300 and $350 \mu \mathrm{M}$. (B) Two other egl-30(rf) mutants, ad810, n715n1190, and two worm strains carrying the over-expressed genomic rescue constructs, $d p y$-20(e1282);egl30genomic and egl-30(md186); dpy-20(e1282);gfp/egl-30genomic were treated with clozapine at $0,300,400,500 \mu \mathrm{M}$.

\section{Fig. 3. Testing downstream clozapine effects via an established Ga signaling pathway that} regulates Acetylcholine receptor and neuropeptide release in $C$. elegans. Adapted from

Perez-Mansilla and Nurrish (2009). The green colored components indicate mutants that are resistant to clozapine; the red colored components indicate mutants that are susceptible to clozapine; and the orange colored components indicate mutants that are phenotypically similar to wild type strains. Mutants in the black components were not tested. 
458 Fig. 4. Characterization of the egl-30 suppressors. (A) N2, MT1434 and two EAB66-67

459 suppressor strains were treated with $1 \mu \mathrm{M}$ aldicarb and examined for movement at $0,0.5,1,1.5$, $4602,2.5,3,3.5,4,4.5 \mathrm{hrs}$. The data are from triplicated experiments with total numbers of tested

461 worms N=70. (B) Locomotion assays of the N2, MT1434 and EAB66-67 suppressor strains.

462 There are statistically significant differences in phenotype among these four strains, $\mathrm{P}<0.001$.

463 The data are from triplicated experiments with a total number of tested worms $\mathrm{N}=35$. (C) Egg

464 retention assays of the wild type N2, MT1434 and EAB66-67 strains. Comparison of these four

465 strains again shows statistically significant differences, $\mathrm{P}<0.05$. The data are from triplicated

466 experiments with a total number of tested worms $N=60$. (D) Pharyngeal pumping assays of wild

467 type (grey bar), MT1434 (black bar) and eight MT1434 suppressor strains (EAB66-71, 73, 74)

468 (color bars). Comparisons between each of the suppressors and the MT1434 strain show

469 statistically significant differences, but differences are not observed between the suppressor

470 bearing strains and wild type strains. (* indicates $\mathrm{p}<0.001$ between each of the mutants and

471 MT1434.) The data are from triplicated experiments with a total number of tested worms $\mathrm{N}=30$. 
473 Table 1. Summary of drug assays on worm strains in known C. elegans Ga signaling

474 transduction. +: Weak suppressor, ++: Intermediate suppressor, +++: Strong suppressor, -:

475 Weak enhancer, --: Intermediate enhancer, ---: Strong enhancer, \pm : Wild-type.

\begin{tabular}{|c|c|c|c|c|c|c|c|c|}
\hline Ortholog in & Gene & Allele & Strain & \multicolumn{4}{|c|}{ Developmental assays } & Concluded \\
\hline $\mathrm{G} \alpha_{0}$ & goa-1 & $s a 734$ & DG1856 & \pm & \pm & -- & & WT \\
\hline PLC $\beta$ & egl-8 & $n 488$ & MT1083 & ++ & + & \pm & & Suppressor \\
\hline HMUNC13 & unc-13 & $e 51$ & MT7929 & + & - & \pm & & WT \\
\hline DGKQ & $d g k-1$ & sy428 & PS2627 & ++ & +++ & + & & Suppressor \\
\hline PRKCE & $p k c-1$ & ok563 & RB781 & -- & -- & ++ & + & WT \\
\hline GNEF & unc-73 & e936 & CB936 & + & \pm & \pm & & WT \\
\hline RGS6,7,9,11 & eat-16 & sa609 & JT609 & \pm & -- &.- & - & Enhancer \\
\hline Calcineurin B & $c n b-1$ & jh103 & KJ300 & -- & -- & -- & -- & Enhancer \\
\hline None & $r s b p-1$ & $v s 163$ & LX1270 & -- & -- & -- & & Enhancer \\
\hline Synembryn-A & ric- 8 & $m d 303$ & RM1702 & ++ & +++ & ++ & & Suppressor \\
\hline GNA12 and 13 & gpa-12 & $p k 322$ & NL594 & \pm & \pm & \pm & & WT \\
\hline GNAL and $\mathrm{S}$ & $g s a-1$ & $c e 81$ & KG421 & \pm & \pm & \pm & & WT \\
\hline ADCY9 & $a c y-1$ & $c e 2$ & KG518 & \pm & \pm & \pm & & WT \\
\hline PDE4A-D & $p d e-4$ & $c e 268$ & KG744 & \pm & \pm & \pm & & WT \\
\hline $\begin{array}{c}\text { PRKAR1A-B, } \\
\text { CNBD1 }\end{array}$ & kin-2 & ce179 & KG532 & \pm & \pm & \pm & & WT \\
\hline
\end{tabular}


Table 2. Candidate mutated genes of $e g l-30(n 686)$ suppressors revealed by whole-genome sequencing.

\begin{tabular}{|c|c|c|c|c|c|}
\hline $\begin{array}{l}\text { Suppre } \\
\text { ssor }\end{array}$ & Location & Gene name or putative function & Site & $\begin{array}{c}\text { nn } \\
\text { change }\end{array}$ & $\begin{array}{c}\text { AA } \\
\text { change }\end{array}$ \\
\hline \multirow{4}{*}{ EAB66 } & F08G5.7 /IV & clec-184 & 12433358 & $\mathrm{C} / \mathrm{T}$ & $\mathrm{Q} /$ Stop \\
\hline & M02b1.1/IV & $s r f-3$ & 12850684 & $\mathrm{C} / \mathrm{T}$ & $\mathrm{Q} /$ Stop \\
\hline & $\mathrm{C} 31 \mathrm{~B} 8.7 / \mathrm{V}$ & No info, only in nematodes & 2901829 & $\mathrm{C} / \mathrm{T}$ & $\begin{array}{l}\text { Splicing } \\
\text { site }\end{array}$ \\
\hline & T08A9.1/X & atg-11 & 7339350 & $\mathrm{C} / \mathrm{T}$ & $\mathrm{Q} / \mathrm{Stop}$ \\
\hline \multirow{2}{*}{ EAB67 } & T13B5.7/II & lips-13 & 1115919 & $\mathrm{G} / \mathrm{A}$ & $\mathrm{Q} /$ Stop \\
\hline & C41A3.1/V & fasn-1 (fatty acid synthase) & 5430972 & $\mathrm{C} / \mathrm{T}$ & $\mathrm{Q} /$ Stop \\
\hline \multirow{5}{*}{ EAB68 } & $\begin{array}{c}\text { Y39H10A.4/ } \\
\text { V }\end{array}$ & Not known function; Only in nematode & 3733499 & $\mathrm{C} / \mathrm{T}$ & $\begin{array}{l}\text { Splicing } \\
\text { site }\end{array}$ \\
\hline & $s r j-27 / \mathrm{V}$ & $\begin{array}{l}\text { Predicted to have transmembrane signaling } \\
\text { receptor activity, based on protein domain } \\
\text { information. Only exists in nematode }\end{array}$ & 15126479 & $\mathrm{G} / \mathrm{A}$ & $\mathrm{Q} /$ Stop \\
\hline & $\mathrm{zc} 13.10 / \mathrm{X}$ & Not known function; Only in nematode & 902597 & $\mathrm{~T} / \mathrm{C}$ & $\begin{array}{l}\text { Initial } \\
\mathrm{M} / \mathrm{V}\end{array}$ \\
\hline & F21G4.3/X & Not known function; Only in nematode & 9896512 & $\mathrm{C} / \mathrm{T}$ & R/Stop \\
\hline & zc506.1/X & $\begin{array}{l}\text { Ortholog of human EDEM3 (ER degradation } \\
\text { enhancer); predicted to have mannosyl- } \\
\text { oligosaccharide 1,2-alpha-mannosidase } \\
\text { activity and calcium ion binding activity, } \\
\text { based on protein domain information. }\end{array}$ & 9963398 & $\mathrm{C} / \mathrm{T}$ & $\mathrm{Q} /$ Stop \\
\hline \multirow[b]{2}{*}{ EAB69 } & clec-131/I & C-type lectin, only existed in nematode. & 3575866 & $\mathrm{C} / \mathrm{T}$ & W/Stop \\
\hline & $r m d-3 / I$ & $\begin{array}{l}\text { Ortholog of human RMDN2 and RMDN3 } \\
\text { (regulator of microtubule dynamics). }\end{array}$ & 11339397 & $\mathrm{C} / \mathrm{T}$ & $\begin{array}{c}\text { Splicing } \\
\text { site }\end{array}$ \\
\hline \multirow[b]{2}{*}{ EAB70 } & Y87G2A.7/I & nyn-2, involved in RNAi & 13574346 & $\mathrm{C} / \mathrm{T}$ & $\mathrm{Q} /$ Stop \\
\hline & $\begin{array}{l}\text { Y66D12A.14 } \\
\text { /III }\end{array}$ & Aminoadipate-semialdehyde dehydrogenase & 11544129 & $\mathrm{C} / \mathrm{T}$ & $\mathrm{Q} /$ Stop \\
\hline \multirow[b]{2}{*}{ EAB71 } & ZK1055.7/V & Involved in innate immune response & 6603050 & $\mathrm{G} / \mathrm{A}$ & $\mathrm{Q} /$ Stop \\
\hline & C41A3.1/X & $\begin{array}{l}\text { Ortholog of human FASN (fatty acid } \\
\text { synthase). }\end{array}$ & 5430972 & $\mathrm{C} / \mathrm{T}$ & $\mathrm{Q} /$ Stop \\
\hline \multirow[t]{2}{*}{ EAB73 } & unc-89 & $\begin{array}{l}\text { Encodes several protein isoforms variably } \\
\text { characterized by the presence or absence of } \\
\text { SH3, DH, PH, immunoglobulin and myosin } \\
\text { light chain kinase (MLCK)-like protein } \\
\text { kinase domains }\end{array}$ & 4082080 & $\mathrm{~A} / \mathrm{T}$ & R/Stop \\
\hline & Y54B9A.1 & Kinesin-like protein & 8078419 & $\mathrm{G} / \mathrm{A}$ & W/Stop \\
\hline \multirow[b]{2}{*}{ EAB74 } & $s r v-17$ & 7TM GPCR, serpentine receptor class v (Srv) & 5869831 & $\mathrm{C} / \mathrm{T}$ & $\begin{array}{l}\text { Splicing } \\
\text { site }\end{array}$ \\
\hline & F23D12.2 & $\begin{array}{l}\text { Encodes a protein containing an F-box and } \\
\text { FTH/DUF38 motifs, mediating protein- } \\
\text { protein interaction. }\end{array}$ & 14416566 & $\mathrm{G} / \mathrm{A}$ & $\mathrm{R} /$ Stop \\
\hline
\end{tabular}


bioRxiv preprint doi: https://doi.org/10.1101/101998; this version posted January 24, 2017. The copyright holder for this preprint (which was not certified by peer review) is the author/funder, who has granted bioRxiv a license to display the preprint in perpetuity. It is made available under aCC-BY-NC 4.0 International license.

Figure 1
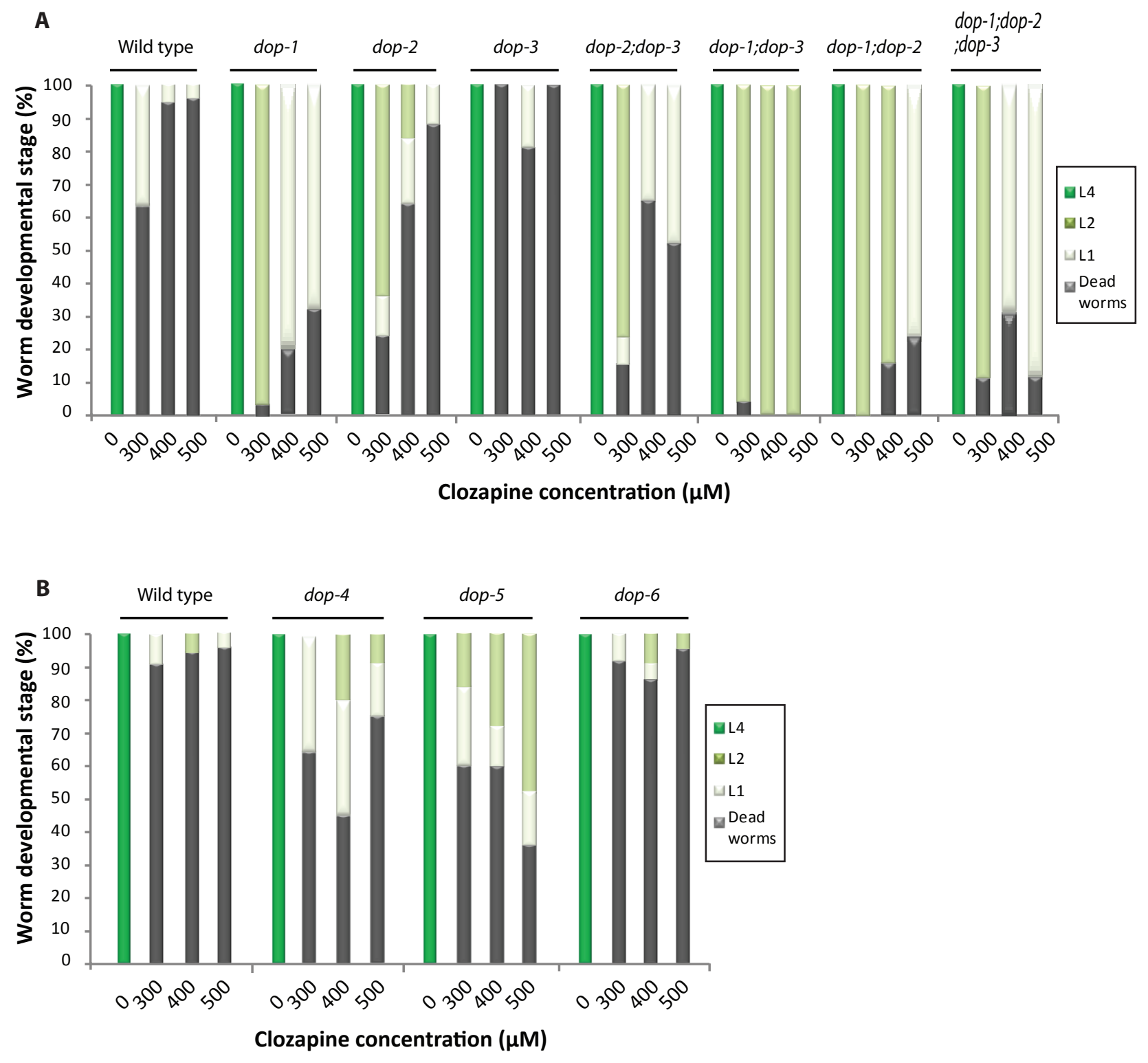
bioRxiv preprint doi: https://doi.org/10.1101/101998; this version posted January 24, 2017. The copyright holder for this preprint (which was not certified by peer review) is the author/funder, who has granted bioRxiv a license to display the preprint in perpetuity. It is made available under aCC-BY-NC 4.0 International license.

Figure 2

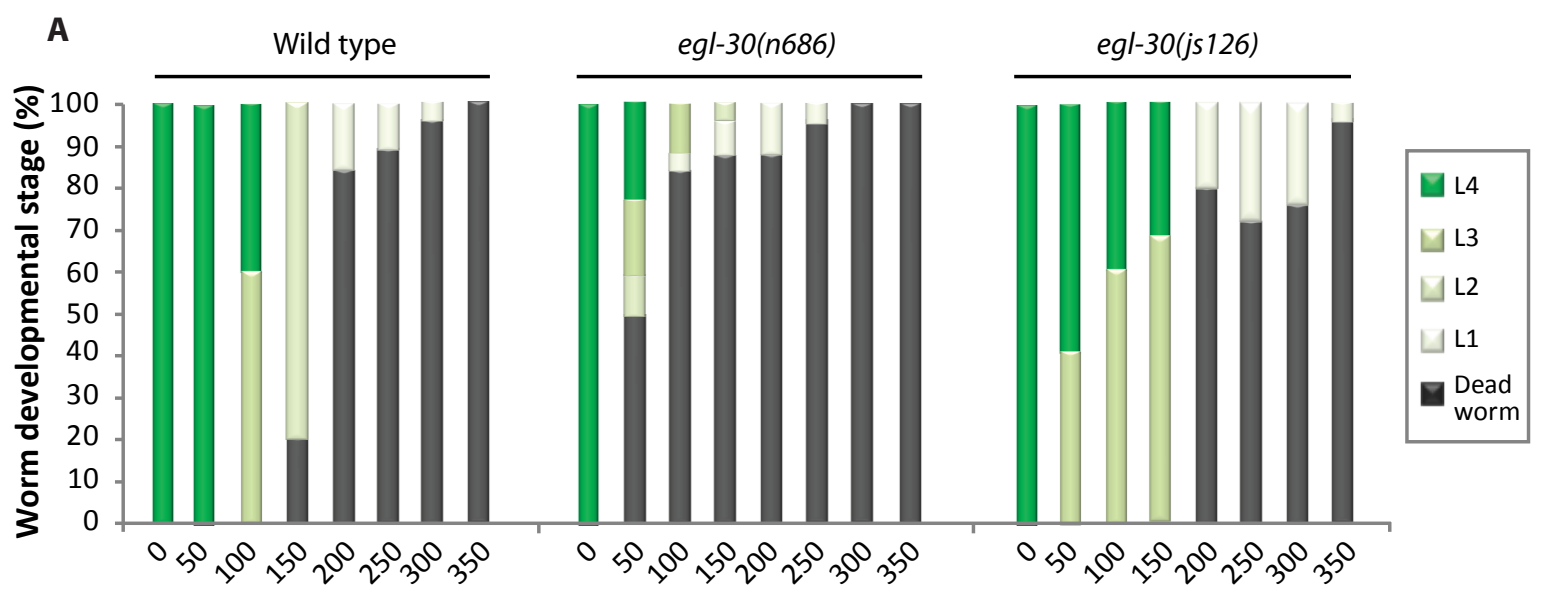

Clozapine concentration ( $\mu \mathrm{M})$

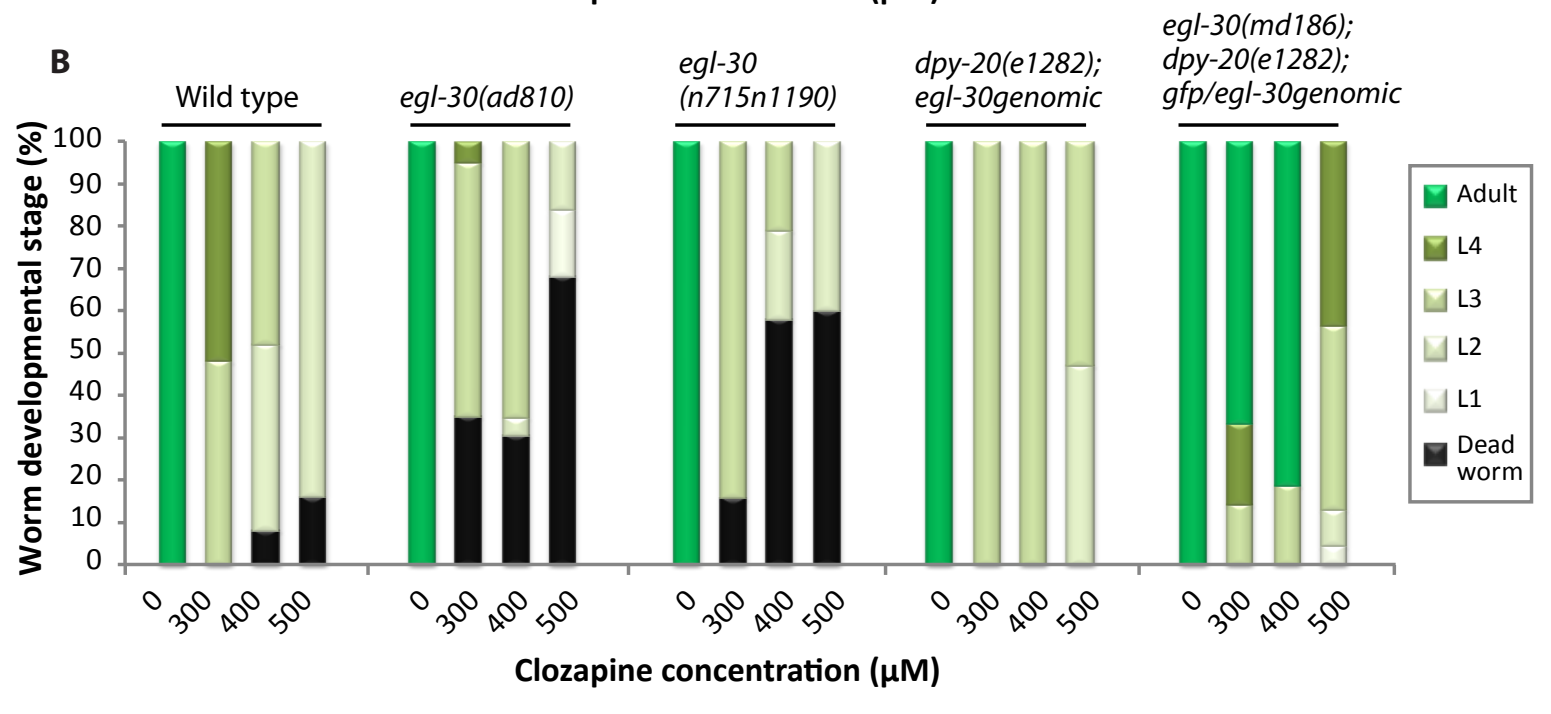


bioRxiv preprint doi: https://doi.org/10.1101/101998; this version posted January 24, 2017. The copyright holder for this preprint (which was not certified by peer review) is the author/funder, who has granted bioRxiv a license to display the preprint in perpetuity. It is made available under aCC-BY-NC 4.0 International license.

\section{Figure 3}

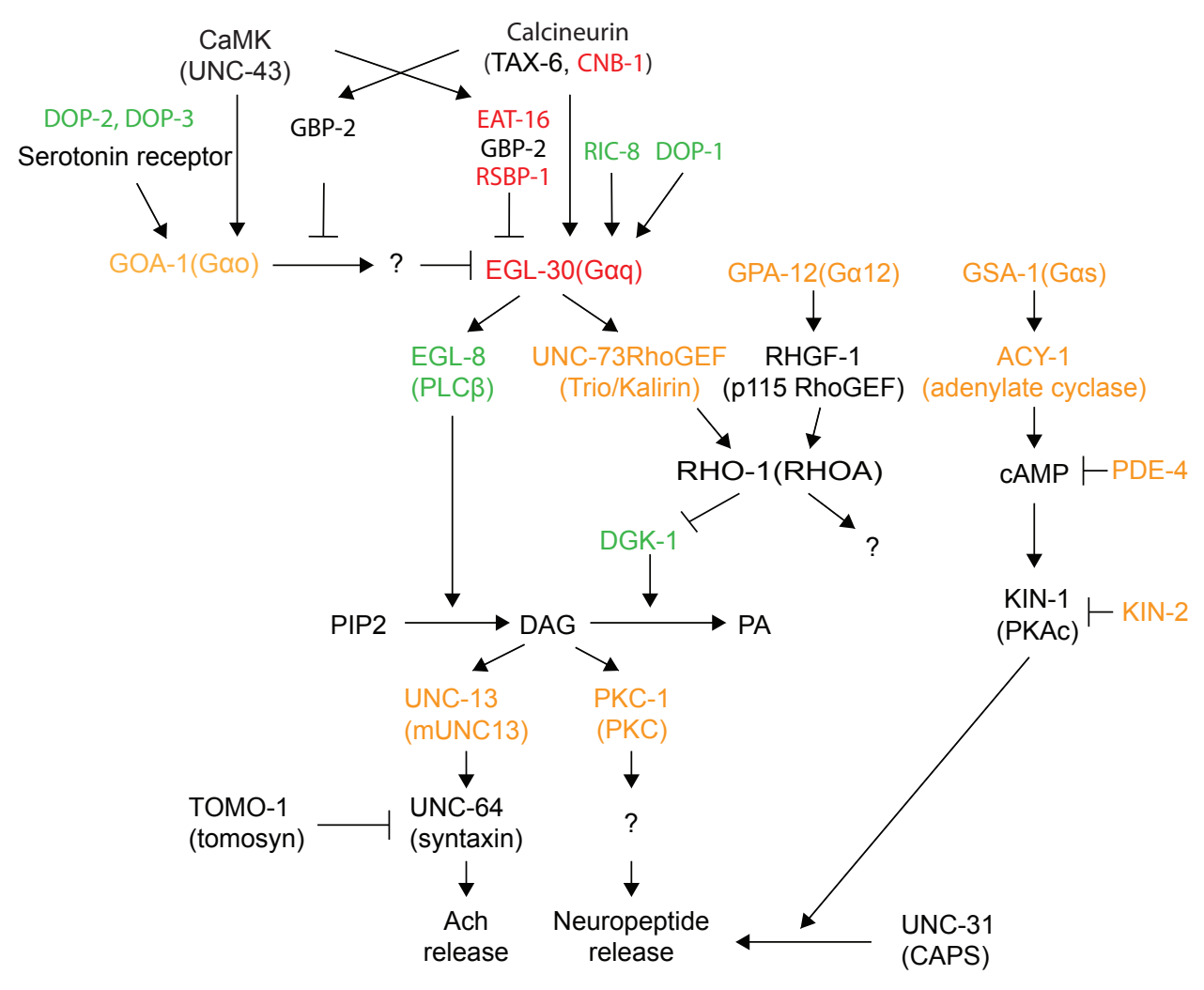


bioRxiv preprint doi: https://doi.org/10.1101/101998; this version posted January 24,2017 . The copyright holder for this preprint (which was not certified by peer review) is the author/funder, who has granted bioRxiv a license to display the preprint in perpetuity. It is made available under aCC-BY-NC 4.0 International license.

Figure 4

A

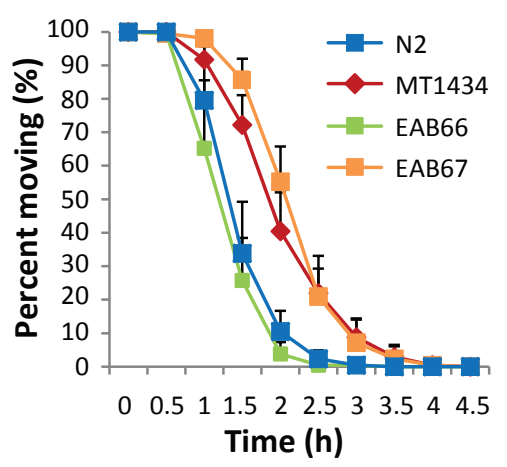

D

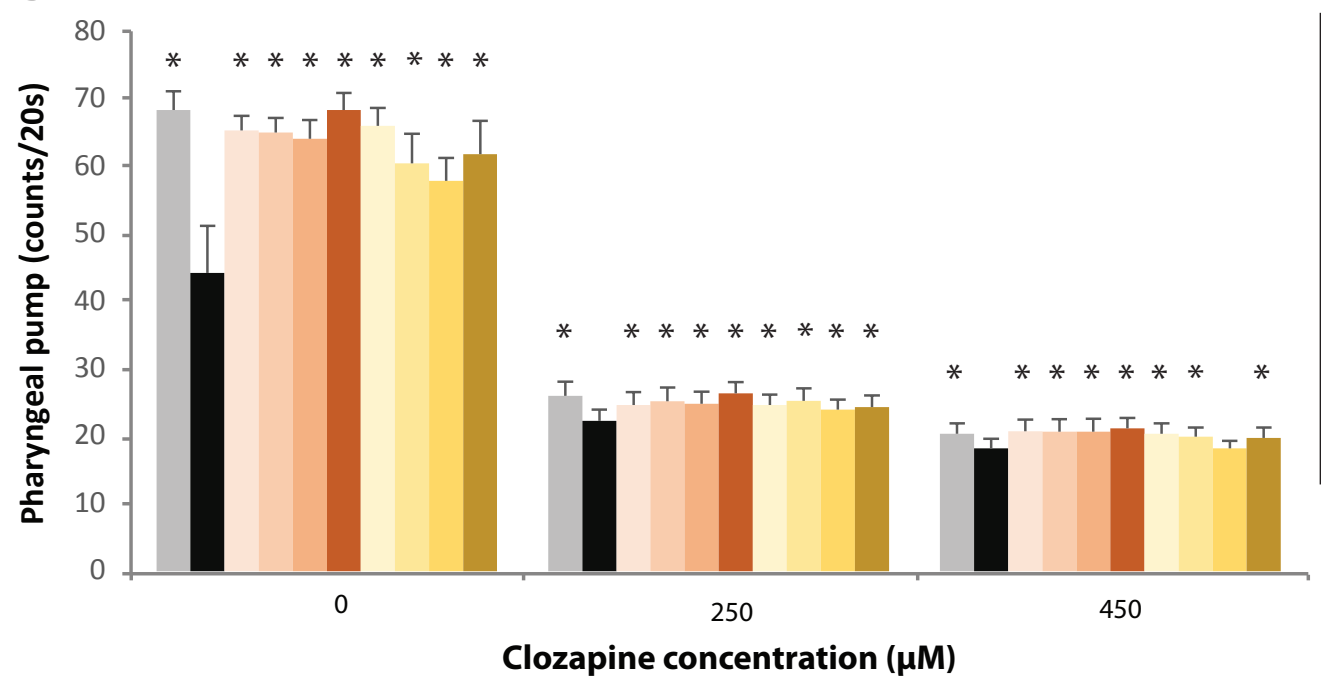

B

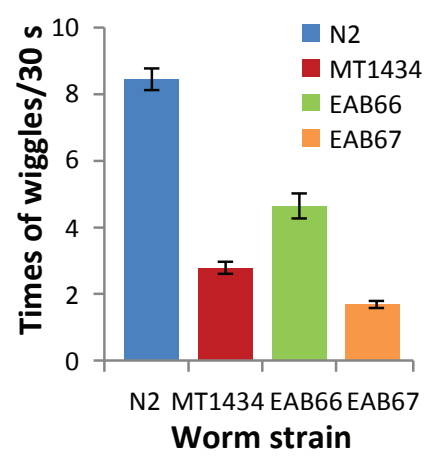

C

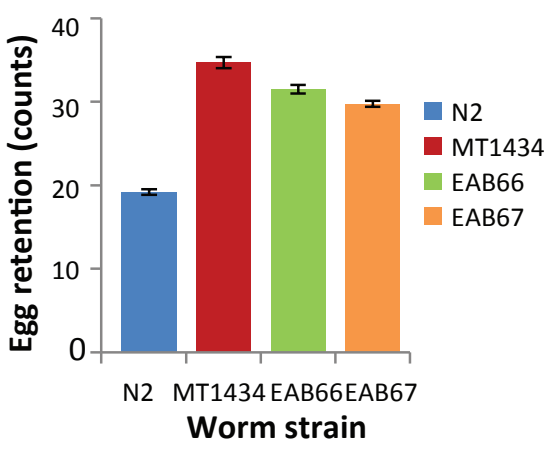

N2

- MT1434

EAB66

EAB67

EAB68

- EAB69

EAB70

EAB71

EAB73

- EAB74 